\title{
Condições de espaços públicos destinados a prática de Atividades Físicas na cidade de Pelotas/RS/Brasil
}

\author{
Public area conditions and physical activity practice in the city of Pelotas/RS/ \\ Brazil
}

\author{
Marcelo Cozzensa da Silva ${ }^{1,2}$ \\ Ânderson Barbosa da Silva ${ }^{1}$ \\ Tales Emilio Costa Amorim ${ }^{2,3,4}$ \\ 'Escola Superior de Educação \\ Física,Universidade Federal de Pelotas, \\ RS, Brasil. \\ ${ }^{2}$ Grupo de Estudos em Epidemiologia \\ da Atividade Física (GEEAF), UFPel \\ ${ }^{3}$ Programa de Pós-graduação em \\ Epidemiologia, UFPel, Pelotas, RS, \\ Brasil. \\ ${ }^{4}$ Instituto Federal Sul Riograndense, \\ Campus Camaquã, RS, Brasil.
}

\begin{abstract}
Resumo
As condições estruturais públicas são determinantes para aumentar o número de inativos fisicamente já que grande parte da população não tem acesso a lugares privados para a realização de atividades físicas. Com isso, os parques e as praças, constituem os principais exemplos de espaços públicos destinados ao lazer. O presente estudo teve o objetivo de realizar um diagnóstico das condições de parques e praças do município de Pelotas para a prática de lazer e atividades físicas. Foi conduzido um estudo observacional descritivo na zona urbana da cidade de Pelotas-RS. Os ambientes foram avaliados de acordo com os seis domínios que compõem o instrumento BRAT-DO. Foram visitados um total de 63 praças/ parques, distribuídos nos seis bairros do município. As áreas mais freqüentes para atividades nos locais avaliados foram os espaços verdes $(85,7 \%)$ e campos de futebol $(47,6 \%)$. No domínio segurança, $66,7 \%$ das praças/parques foram consideradas muito inseguro/inseguro, sendo que $95,2 \%$ deles não podiam ser trancados e 1/5 não apresentava qualquer iluminação na área alvo. Em relação à existência de quadras esportivas, 95,2\% das praças/parques não possuíam esses locais. Não foram encontradas trilhas ou pistas de caminhada assim como áreas destinadas à realização de alongamentos, exercícios e ginástica. A existência de playground foi observada em $31,8 \%$ dos locais visitados e em $47,6 \%$ foram encontrados campo para a prática de esportes. Apesar de distribuídas por toda a cidade as praças/parques carecem de uma melhor estruturação além de uma melhora na conservação do ambiente.
\end{abstract}

Palavras-chave: Ambiente; Ambiente e saúde pública; Atividade motora.

\section{ENDEREÇOPARA CORRESPONDÊNCIA}

\section{Marcelo Cozzensa da Silva}

PPG em Educação Física, Universidade Federal de Pelotas

Rua Luis de Camões, 625

Pelotas, RS

96055-630

cozzensa@terra.com.br

\begin{abstract}
The public structural conditions are crucial to increase the number of physically inactivity individuals, since much of the population has no access to private places for physical activity. Parks and squares are the main examples of public spaces for leisure. This study aimed to perform a diagnosis of the conditions of parks and squares of Pelotas city for leisure and physical activities practice. It was a descriptive observational study conducted in the urban area of Pelotas. Environments were evaluated through the six areas that make up the instrument BRAT-DO. We visited a total of 63 squares/parks, distributed in six areas of the municipality. The most common areas for activities were green spaces (85.7\%) and soccer (47.6\%). In terms of security, $66.7 \%$ of squares/parks were considered very unsafe/insecure, with $95.2 \%$ of them could not be locked and $1 / 5$ did not show any light in the target area. Regarding the existence of sports, $95.2 \%$ of squares/parks had no such places. There were no trails or hiking trails as well as areas for the achievement of stretching, exercise and fitness. The existence of playground was observed in $31.8 \%$ of the places visited and $47.6 \%$ of squares/ parks presented sports field. Although distributed throughout the city squares/parks need a better structure than an improvement in conservation the environment. Keywords: Environment; Environment and public health; Motor activity.
\end{abstract}




\section{INTRODUÇÃO}

Reconhecidamente, a participação em atividades físicas regulares reduz o risco de doenças coronarianas, diabetes, hipertensão, câncer de cólon e mama e depressão. Somado a isso, é componente fundamental para o balanço energético e controle de peso ${ }^{1,2}$.

Apesar de todos os benefícios, vários estudos relatam haver crescimento na prevalência de inatividade física em países desenvolvidos e em desenvolvimento, independentemente do gênero, idade, nível socioeconômico e educacional 1,3. Esse fator de grande preocupação chamou a atenção da Organização Mundial da Saúde (OMS) que incluiu a atividade física em sua lista de prioridades. Contudo, se faz necessária uma promoção de saúde que, de acordo com Candeias, é uma combinação de apoios educacionais e ambientais que visam atingir ações e condições de vida conducentes à saúde, sendo que, a combinação refere-se à necessidade de mesclar os múltiplos determinantes da saúde, com múltiplas intervenções ou fontes de apoio ${ }^{4}$.

Figueira Junior descreve que, programas de intervenção de atividades físicas, têm buscado, pelo menos, dois grandes objetivos: 10) aumentar o conhecimento populacional dos benefícios de um estilo de vida; e $2^{\circ}$ ) aumentar a participação populacional em atividades físicas, no dia-a-dia, sem grandes alterações das atividades cotidianas, bem como em períodos de lazer ${ }^{5}$. Porém, é interessante ressaltar que o comportamento ativo sofre interferências da dinâmica de vida dos indivíduos (trabalho, aspectos corporais, fatores psicológicos, crenças e conhecimentos) e de fatores ambientais (segurança, moradia, aspectos econômicos, saúde básica, educação, transporte e locais) que podem ter uma relação determinante para o envolvimento populacional em atividades físicas.

Contudo, quando se pensa em discutir o lazer e a atividade física, dificilmente o olhar do profissional de educação física tem se voltado à análise dos espaços onde esta atividade acontece ${ }^{6}$. As condições estruturais públicas e seus empecilhos são determinantes para aumentar o número de sedentários, já que grande parte da população não tem acesso a lugares privados para a realização de atividades físicas. Preocupações desta natureza devem se tornar mais presentes quando está em jogo a relação entre espaço urbano, lazer e contemporaneidade ${ }^{7}$.

De acordo com Santos, os parques e as praças constituem os principais exemplos de espaços públicos para o lazer, podendo se diferenciar em função de suas características funcionais ou morfológicas e se constituir a partir de diferentes paradigmas de lazer ${ }^{6}$. Abercrombie et al. salientam que os parques públicos são locais privilegiados para a prática de atividades físicas, sendo freqüentados por um número grande de sujeitos que fazem desde atividades com baixo gasto energético até atividades como uma corrida exaustiva ${ }^{8}$.

As praças e parques são utilizadas diariamente por pessoas que depositam no espaço público um leque de intencionalidades que vão desde o praticar alguma atividade física até o simples, e tão necessário, descanso. Entretanto, quase nada se sabe a respeito da quantidade e dos atributos físicos e sociais desses locais na cidade de Pelotas - RS, Brasil.

Nesse sentido, o presente estudo teve o objetivo de realizar um diagnóstico das condições de parques e praças do município de Pelotas para a prática de lazer e atividades físicas.

\section{MÉTODOS}

Foi conduzido um estudo observacional descritivo na zona urbana da cidade de Pelotas-RS sendo que a coleta de dados compreendeu o período de outubro e novembro de 2010.

O procedimento para a coleta de dados ocorreu através de visitas diretas as praças e parques. Para a obtenção do registro de parques e praças existentes na zona urbana do município foi realizado, primeiramente, contato com a Secretaria de Urbanismo da cidade de Pelotas. Posteriormente, as Secretarias de Serviços Urbanos e de Qualidade Ambiental foram contatadas para obtenção da listagem. Além disso, foi realizado contato com a Faculdade de Arquitetura e Urbanismo da UFPel, para a averiguação e, se necessário, complementação da listagem dos locais a serem visitados.

Para avaliar as condições dos locais visitados foi utilizada a versão traduzida e adaptada do instrumento BRAT-DO (Bedimo-Rung Assessment Tools-Direct Observation) que qualifica o ambiente social, físico e político dentro dos limites de parques ${ }^{9}$. O instrumento original foi desenvolvido por uma série de estudiosos utilizando o método Delphi e caracteriza-se por uma avaliação visual com o objetivo de identificar e avaliar características físicas dos parques baseado em uma estrutura conceitual que possui seis domínios (aspectos, condições, acesso, estética, segurança e política do parque.), relacionados com a existência e a qualidade dos atributos passíveis de aumentar o potencial de uso do local, para a prática de atividades física (Quadro 1).

$\mathrm{O}$ instrumento original apresentou fidedignidade considerada de boa a excelente através de análise de concordância entre avaliadores, com resultados variando entre $67,3 \%$ a $100 \%$ de concordância (média de 87,5\%). A validade dos domínios foi analisada comparando avaliações dos observadores treinados com a realizada por especialistas e apresentou uma média de concordância de 78,7\%, com valor mínimo de $42,8 \%$ e máximo de $99,3 \%{ }^{9}$.

A versão utilizada no estudo foi adaptada do instrumento original ao contexto brasileiro, porém mantendo os mesmos domínios, propostos na versão primária, com exclusão

\begin{tabular}{|l|l|} 
Quadro 1 & \multicolumn{1}{c|}{$\begin{array}{l}\text { Domínios do instrumento de avaliação } \\
\text { dos parques e praças* }\end{array}$} \\
\hline Domínios & \\
\hline Aspectos & $\begin{array}{l}\text { Caracterizado pelo número, tamanho e tipo de } \\
\text { facilidades, programas oferecidos, diversidade } \\
\text { de equipamentos e tipos de uso do local }\end{array}$ \\
\hline Condições & $\begin{array}{l}\text { Relacionado à manutenção e reparo nas } \\
\text { estruturas e instalações do parque e } \\
\text { incivilidades (lixo, sujeira e pichações) }\end{array}$ \\
\hline Acesso & $\begin{array}{l}\text { Sob quatro aspectos: viabilidade de acesso, } \\
\text { acesso equitativo, acesso individual, para se } \\
\text { chegar ao parque e acesso dentro do parque }\end{array}$ \\
\hline Estética & $\begin{array}{l}\text { Composta por atrativos percebidos, aparência } \\
\text { dos diversos elementos no parque, e, ainda, } \\
\text { como estão dispostos os aspectos físicos do } \\
\text { parque }\end{array}$ \\
\hline Segurança & $\begin{array}{l}\text { Refere-se à segurança pessoal dos usuários do } \\
\text { parque, tanto com respeito à criminalidade, } \\
\text { quanto dos riscos à saúde. }\end{array}$ \\
\hline $\begin{array}{l}\text { Política } \\
\text { do parque }\end{array}$ & $\begin{array}{l}\text { Caracteriza-se pelo plano de funcionamento, } \\
\text { práticas de gerenciamento e custo para o uso } \\
\text { do local, disponíveis em informativos ou } \\
\text { mensagens }\end{array}$ \\
\hline
\end{tabular}

*Traduzido do instrumento original publicado por Begimo-Rung et al. (2006) 
das questões referentes a observação das piscinas, as quais eram inexistentes nesses espaços. Para tanto, o instrumento e o protocolo originais passaram por um processo de tradução, revisão e teste ${ }^{10}$.

A coleta de dados foi realizada durante o período da tarde e o tempo de permanência no local foi determinado pelo tamanho da área a ser percorrida. O período de observação variou entre 10 e 40 minutos. Todos os locais selecionados foram avaliados pelo pesquisador responsável.

Antes da avaliação foi necessário identificar, mapear, numerar e ordenar todas as áreas dos parques e praças, denominadas áreas alvo, de maneira a organizar o percurso de observações. Para tanto foram utilizados mapas fornecidos por uma professora de uma Faculdade de Arquitetura da cidade, já que os mesmos não foram disponibilizados pelas secretarias de urbanismo, serviços urbanos e qualidade ambiental do município.

Para avaliação das praças e parques, o avaliador percorreu os mesmos (a pé ou de bicicleta) com o intuito de não perder qualquer detalhe importante para o processo de avaliação. Nos locais de maior metragem quadrada foi definido um ponto de partida e uma rota de avaliação a seguir. $\mathrm{O}$ avaliador, colocado no ponto de partida, de frente para a área a ser avaliada, deslocava-se sempre para o lado direito, até o local ser totalmente percorrido.

Os dados registrados no formulário foram digitados no programa Excel for Windows e as análises conduzidas no programa estatístico Stata 10.0. A análise univariada calculou médias com seus respectivos desvios padrão para variáveis contínuas e cálculos de proporção e seus intervalos de confiança para variáveis categóricas.

\section{RESULTADOS}

Foram visitados um total de 63 parques e praças da zona urbana do município de Pelotas. Encontram-se assim distribuídos os parques e praças da cidade: 16 no bairro Centro, 15 no bairro Fragata, 13 no bairro Três Vendas, 10 no bairro Areal, 7 no bairro Porto e 3 no bairro Laranjal.

As áreas mais freqüentes existentes para atividades nos locais avaliados foram os espaços verdes $(85,7 \%)$, campos de futebol $(47,6 \%)$ e playground (31,8\%) (figura 1).

A fonte de geração de sombra mais freqüente nas áreas alvo (subdivisões do parque pré-determinados pelos pesquisadores na qual não estão incluídas ruas e as áreas de atividade - quadras, espaços verdes, caminhos, playgoround, campo de jogos) foram as árvores (68,3\%), seguido de prédios $(31,7 \%)$ e abrigos (3,2\%) (tabela 1). Em torno de $20,0 \%$ das praças/parques não apresentavam qualquer

Características de praças e parques da cidade de Pelotas, RS, Brasil. 2011 ( $n=63$ )

\begin{tabular}{|c|c|c|}
\hline Características praças e parques & $\mathrm{N}$ & $\%$ \\
\hline \multicolumn{3}{|l|}{ Fonte de sombra* } \\
\hline Árvores & 43 & 68,3 \\
\hline Prédios & 20 & 31,7 \\
\hline Abrigos & 2 & 3,2 \\
\hline \multicolumn{3}{|c|}{ Praças/parques pode ser trancados } \\
\hline Não & 60 & 95,2 \\
\hline Sim & 3 & 4,8 \\
\hline \multicolumn{3}{|l|}{ Existe iluminação nas áreas alvo } \\
\hline Não & 15 & 23,8 \\
\hline Sim & 48 & 76,2 \\
\hline \multicolumn{3}{|l|}{ Existe abrigo (áreas cobertas) } \\
\hline Não & 62 & 98,4 \\
\hline $\operatorname{Sim}$ & 1 & 1,6 \\
\hline \multicolumn{3}{|l|}{ Bebedouros } \\
\hline Não & 63 & 100 \\
\hline Sim & 0 & 0 \\
\hline \multicolumn{3}{|l|}{ Banheiros } \\
\hline Não & 55 & 87,3 \\
\hline Sim & 8 & 12,7 \\
\hline \multicolumn{3}{|l|}{ Quadras esportivas } \\
\hline Não & 60 & 95,2 \\
\hline Sim & 3 & 4,8 \\
\hline \multicolumn{3}{|l|}{ Trilhas e pistas de caminhada } \\
\hline Não & 63 & 100 \\
\hline Sim & 0 & 0 \\
\hline \multicolumn{3}{|l|}{ Playground } \\
\hline Não & 43 & 68,2 \\
\hline Sim & 20 & 31,8 \\
\hline
\end{tabular}

* Fonte de sobre supera o $\mathrm{n}=63$ por haver em alguns locais mais de uma fonte.

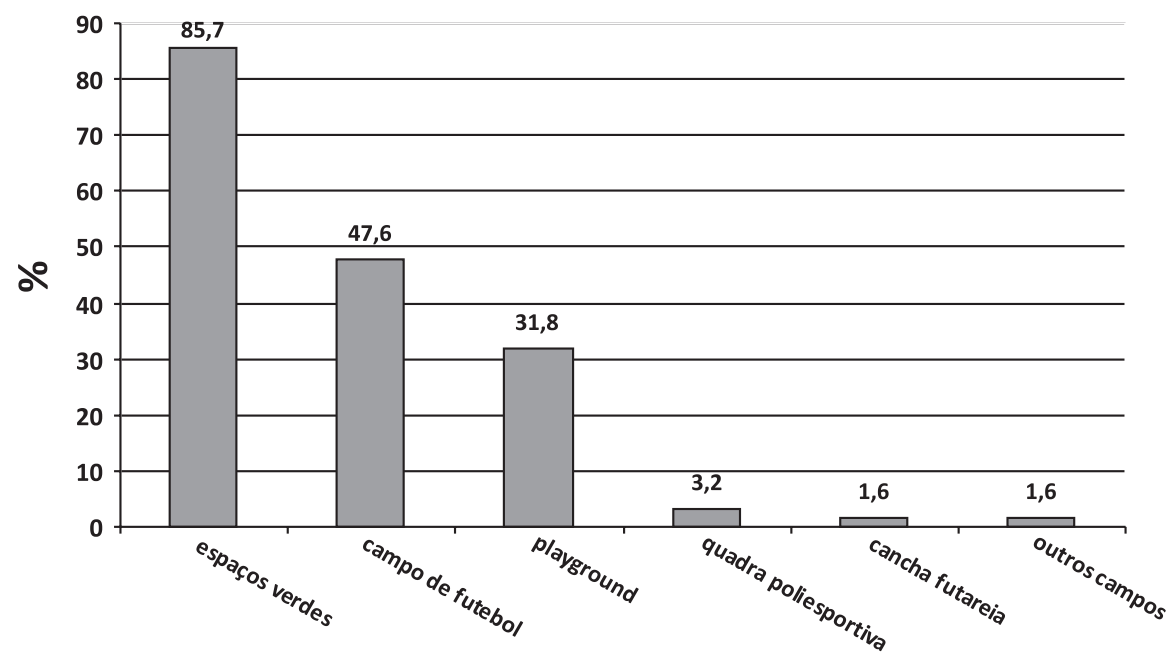


banco no mapa da área alvo. Dentre as que apresentavam bancos $(n=50), 74 \%$ encontravam-se, em condições gerais, muito ruim/ruim.

Quase a totalidade das praças/parques $(95,2 \%)$ não podiam ser trancados e, aproximadamente, 1/5 deles não apresentava qualquer iluminação na área alvo (tabela 1).

A existência de abrigos, banheiros, bebedouros e locais de compra também foram avaliadas. Em quase totalidade das praças/parques $(98,4 \%)$ nenhum abrigo foi encontrado e nenhum dos bebedouros existentes funcionava; em 87,3\% não havia banheiro (tabela 1) e em 81,0\% não existia área de compra de bebidas e comida.

Em relação à existência de quadras esportivas, em $95,2 \%(n=60)$ das praças/parques não existem quadras específicas para a prática de esportes (tabela 1). Entre as que possuem $(n=3)$ todas as quadras são em ambientes externos, sendo duas descobertas e uma coberta. Duas quadras são poliesportivas e uma apresenta somente estrutura (postes de rede) para a prática do voleibol. Em uma das quadras o piso é de cimento, em nas outras são de tábua emborrachada e areia. Duas quadras não apresentam marcações visíveis das linhas que demarcam os desportos e possuem estruturas quebradas. Quanto à iluminação, uma quadra não apresenta qualquer ponto de luz. Em relação à segurança e regramento, duas das quadras não podem ser trancadas, duas não necessitam de reserva para utilização e nenhuma especifica regras para a prática de esportes e outras atividades.

Não foi encontrada nenhuma trilha ou pista de caminhada em qualquer uma das 63 praças existentes na zona urbana do município. Do mesmo modo, a totalidade dos locais visitados não apresentou quaisquer áreas destinadas à realização de alongamentos, exercícios e ginástica (tabela 1).

A existência de playground foi observada em 31,8\% $(\mathrm{N}=20)$ dos locais visitados (tabela 1). Dos equipamentos existentes nos playgrounds, os mais frequentemente encontrados foram escorregador $(49,2 \%)$, cadeira de balanço $(30,2 \%)$, gangorra $(28,6 \%)$ e aparelho de escalada $(6,3 \%)$. A maior parte dos terrenos onde estavam localizados os playgrounds era de grama, relva ou solo (85\%). Alguma/muita deteriorização (corrosão, material dos objetos) foi observada em $65 \%$ dessas áreas, sendo que em $35 \%$ faltavam ou existiam materiais quebrados. Nenhum dos playgrounds pode ser trancado ou possui cerca. Também a totalidade deles não possui recomendações de uso e informações especificando idade ou peso para brincar em qualquer um dos utilitários existentes.

Em 47,6\% ( $n=30)$ das praças/parques foram encontrados campos para a prática de esportes. Na totalidade desses locais existiam traves de futebol, $10 \%$ apresentavam cerca e 3,3\% possuíam arquibancadas e bebedouros. A intenção majoritária de uso do campo era para a prática de futebol. Apesar da existência de traves de futebol na totalidade dos campos, em $40 \%$ deles essas estruturas encontravam-se quebradas. Em relação à segurança, 96,7\% não podem ser trancadas e 43,3\% não apresentavam iluminação.

Outras áreas de atividades também foram investigadas na pesquisa. Em três praças/parques foram encontradas áreas para outras práticas sendo todas elas externas e descobertas. Patinação, skate, bicicleta freestyle e bocha foram os focos de intenção de utilização desses locais. Para isso havia a existência de uma pista de cimento de esportes radicais (Half pipe) e uma cancha de bocha de terra. Duas delas apresentavam bom nível de conservação (poucas estruturas quebradas) e todas eram iluminadas.

\section{DISCUSSÃO}

No presente estudo verificou-se que mais de $3 / 4$ dos locais visitados apresentavam áreas verdes, o que vai ao encontro do conceito de parques e praças descrito por Barcellos, Kliass e Macedo e Sakata, o qual define-os como espaços livres constituídos de áreas verdes. Em conseqüência da abrangência de áreas verdes, grande predominância de sombra encontrada foi oriunda da presença de árvores, sendo as praças/parques localizados mais próximos a região central tendo, também, a fonte de sombra oriunda dos prédios ${ }^{11-13}$.

Rechia e França, ao observarem as praças do Paraná, perceberam que essas não possuem infraestruturas que possibilitem dinâmicas mais intensas, como diferentes práticas esportivas ${ }^{14}$. Isso se justifica pela falta de disponibilidade de equipamentos que possam se tornar significativos para a população. Desta maneira as praças são concebidas apenas como espaços livres que servem para a quebra de edificação na cidade. Isso gera uma falta de hábito de apropriação desse espaço, o que acaba reduzindo os locais a bancos e monumentos. Isso foi também observado no município de Pelotas, onde o número de quadras esportivas, playgrounds e outras áreas de atividade foram pequenos em relação a espaços verdes e áreas para futebol, que possuem maior facilidade de construção e de manutenção.

Santos relata que na cidade de Porto Alegre-RS, excetuando as praças centrais mais antigas construídas com a finalidade de passeio e contemplação, dificilmente são encontradas praças que não possuam ligação com futebol ${ }^{6}$. Tal relato condiz com a afirmativa de que quase metade dos locais analisados possuem campos de futebol.

Sobre a existência de bancos e iluminação, Gomes e Amorim afirmam que as praças públicas devem ser dotadas de infra-estrutura básica como bancos com encosto, calçadas e iluminação eficiente ${ }^{15}$. Em sua grande maioria, as praças analisadas possuíam bancos, porém seu estado de conservação era péssimo e a iluminação precária.

Estudo de Silva et al. mostrou que a segurança pública nas imediações de parques estimula a prática de atividades físicas, independente de outros fatores sociodemográficos ${ }^{16}$. Parques e praças que apresentam iluminação e podem ser trancados, podem aumentar a visitação para práticas de atividades físicas. Amorim et al. descreve que uma vizinhança segura e ambientes agradáveis em termos estéticos, também se mostram associadas com a prática de atividades físicas ${ }^{17}$. Os dados encontrados no presente estudo ( $23 \%$ das áreas alvo sem iluminação e mais de $60 \%$ de locais considerados inseguros, tanto pela região onde estão localizadas quanto pela falta de portões e grades) podem favorecer o aumento do número de crimes nesses locais, o que, consequentemente, levaria tanto a evasão quanto a não procura dos mesmos para a prática de atividades físicas.

Segundo Cohen et al., parques e praças proporcionam locais para as pessoas caminhar ou correr, além de, alguns, disponibilizarem instalações específicas para esportes, exercícios e outras atividades vigorosas ${ }^{18}$. Inversamente a isso, um baixo número de playgrounds, falta de trilhas e espaços para ginástica e poucas opções para a prática de outras modalidades esportivas foram encontrados no município. Morero et al. afirmam que, apesar do conhecimento acadêmico da importância das áreas verdes urbanas, há uma tendência de se "economizar nos espaços para o lazer", devido ao fato de a manutenção ser muito custosa para o governo e, por parte da população, não haver ajuda na conservação dos espa$\operatorname{ços}^{19}$. Tal fato pode ser confirmado pelo grande número de 
playgrounds que apresentaram problemas de infraestrutura e equipamentos quebrados. Também, é de fácil percepção que a melhoria e ampliação dos equipamentos de lazer não são constantemente reivindicadas e, assim, não são entendidos como uma das prioridades da gestão, ocasionando por muitas vezes um sucateamento e descaso nos já ínfimos e inadequados espaços públicos de lazer ${ }^{20}$. Marcellino ${ }^{21}$ e Cassou ${ }^{10}$ afirmam que, além da luta para a obtenção de novos espaços, é preciso tratar da conservação dos já existentes, visto que, muitas vezes, a solução não está na construção de novos equipamentos, mas na recuperação e revitalização de espaços destinando-os a sua função original, ou, com adaptações necessárias, a outras finalidades.

Em termos de infra-estrutura da praça/parque em geral, poucos lugares visitados dispunham de banheiros, abrigos, bebedouros e áreas de comercialização. Os poucos banheiros existentes analisados, estavam em situação precária e com muita sujeira acumulada. Gonçalves et al. observaram o descaso em relação aos banheiros públicos presentes nas praças que, na maioria das vezes, se apresentam em condições precárias, sendo, em alguns casos, inutilizáveis ${ }^{20}$. Apesar da população precisar utilizar esse espaço, não há manutenção adequada nem relativa preservação dos pontos.

O presente estudo apresenta limitações e pontos positivos que devem ser salientados. $O$ estudo se restringiu a realizar unicamente uma análise quantitativa das praças/parques do município contabilizando seus equipamentos e avaliando somente parte de suas estruturas. Uma análise qualitativa desses lugares, além de uma avaliação mais abrangente em relação a todas as áreas públicas destinadas a prática de atividade física e lazer da cidade são necessárias para um diagnóstico mais preciso das condições dos locais que deveriam ser utilizados para tais fins. Como pontos positivos, podemos afirmar que esse é um dos primeiros estudos que avaliou as condições de praças/parques na cidade de Pelotas. Outro ponto importante a ser destacado foi o levantamento realizado pelos pesquisadores, que, juntamente com a Faculdade de Arquitetura, conseguiram mapear a totalidade das praças/ parques da cidade. Tal informação não foi fundamental exclusivamente para a pesquisa mas também para a atualização do cadastro desses locais nas secretarias de Arquitetura e Urbanismo e de Qualidade Ambiental do município.

Parques e praças podem ter um importante papel como facilitadores da prática de atividades físicas ${ }^{10}$. Estudos têm demonstrado que a existência de locais seguros para a prática de atividades físicas próximos as residências, que possuam quadras de esporte e bancos estão associados a prática de atividade física no lazer em adultos e idosos ${ }^{22,23}$.Os resultados encontrados nesse estudo retratam que, apesar de distribuídas por toda zona urbana, as praças e parques do município ainda carecem de uma melhor estruturação além de uma meIhora na conservação do ambiente. Isso pode ser um dos fatores que tem ajudado a fomentar o aumento da prevalência de indivíduos insuficientemente ativos na cidade, que passou de 41,1\% em 2002 para 52,0\% em $2007^{24}$.

Este é o momento do governo e da população redefinirem ações para melhoria e bem estar dos indivíduos, e a estruturação de espaços públicos urbanos, bem equipados, conservados e voltados ao lazer e a prática de atividades físicas são fundamentais para a promoção da qualidade de vida e saúde de todos os indivíduos. Para isso é necessário que, primeiramente, o governo municipal consiga mapear, organizar e disponibilizar as informações de parques e praças da cidade ${ }^{10}$. A parceria da prefeitura com a iniciativa privada (por exemplo, firmas responsáveis pela conservação das estruturas físicas do local e policiamento através da guarda pública municipal) e pública (professor municipal de educação física assessorado por estudantes do curso de educação física da universidade pública) podem ajudar a que os indivíduos procurem cada vez mais esses locais para suas práticas de lazer.

\section{Contribuições dos autores}

Marcelo Cozzensa da Silva supervisionou o trabalho de campo, conduziu as análises, confecção das tabelas e gráfico, interpretação e escrita dos resultados e discussão. Ânderson Barbosa da Silva foi responsável pela coleta de dados, revisão literária e ajudou na escrita final do artigo. Tales Emilio Costa Amorim ajudou na escrita do artigo, em todas as fases.

\section{REFERÊNCIAS}

1. World Health Organization. Global health risks: mortality and burden of disease attributable to selected major risks. Geneva, Switzerland: World Health Organization; 2009.

2. World Health Organization. A guide for population-based approaches to increasing levels of physical activity: implementation of the WHO Global Strategy on Diet, Physical Activity and Health. Geneva, Switzerland: World Health Organization; 2007

3. Ceschini FL. Júnior AF. Barreiras e determinantes para a prática de atividade física em adolescentes. Rev Bras Ci e Mov 2007; 15(1): 29-36.

4. Candeias NMF. Conceitos de educação e de promoção em saúde: mudanças individuais e mudanças organizacionais. Rev Saude Publica 1997; 31 (2):209-213.

5. Figueira Junior AJ. Potencial da mídia e tecnologias aplicadas no mecanismo de mudança de comportamento, através de programas de intervenção de atividade física. Rev Bras Ci e Mov 2000; 8(3): 39-46.

6. Santos ES. Reflexões sobre a utilização de espaços públicos para o lazer esportivo. RA'E GA 2006; 11:25-33.

7. http://www2.ufrgs.br/xiipalops/ArquivosUpload/1007996_22_1268.pdf. Acessado em: 20 de Junho de 2010.

8. Abercrombie LC, Sallis JF, Conway TL et al. Income and racial disparities in access to public parks and private recreation facilities. Am J Prev Med 2008;34(1):.9-15.

9. Bedimo-Rung MA, Cohen D. The significance of parks to physical activity and public health: a conceptual model. Am J Prev Med 2005; 28(2):159-168.

10. Cassou ACN. Características ambientais, freqüência de utilização e nível de atividade física dos usuários de parques e praças de Curitiba, PR. Dissertação de Mestrado, UFPR, Curitiba, Paraná, 2009.

11. Barcellos VQ. Os parques: velhas idéias e novas experiências. Paisagem e ambiente: ensaios. São Paulo: Faculdade de Arquitetura e Urbanismo/FAUUSP, n.13, p. 49-71, dez, 1997.

12. Kliass RG. Parques urbanos de São Paulo e sua evolução na cidade. São Paulo: Pini, 1993.

13. Macedo SS, Sakata F. Parques urbanos no Brasil. São Paulo: Editora da Universidade de São Paulo, 2002

14. Rechia S, França R. O estado do Paraná e seus espaços e equipamentos de esporte e lazer: apropriação, desapropriação ou reapropriação? In: Mezzadri FM.; Cavichiolli FR; Souza DL (Org.). Esporte e Lazer: subsídios para o desenvolvimento e a gestão de políticas públicas. Jundiaí: Fontoura, 2006.

15. Gomes MAS, Amorim MCT. Arborização e Conforto Térmico no Espaço Urbano: estudo de caso nas praças públicas de Presidente Prudente (SP). Caminhos de Geografia 2003; 7(10): 94-106.

16. Silva DAS, Petroski EL, Reis RS. Barreiras e facilitadores de atividades físicas em freqüentadores de parques públicos. Motriz 2009; 15(2): 219-227.

17. Amorim TC, Azevedo Junior MR, Hallal PC. Physical activity levels according to physical and social environmental factors in a sample of adults living in south Brazil. J Phys Act Health 2010; 7: 204-212.

18. Cohen DA, McKenzie TL, Sehgal A, Williamson S, Golinelli D, et al. Contribution of public parks to physical activity. Am J Public Health 2007; 97:509-14.

19. Morero AM, Santos RF, Fidalgo ECC. Planejamento ambiental de áreas verdes: estudo de caso de Campinas-SP. Revista do Instituto Florestal 2007; 19 (1): 19-30.

20. Gonçalves FS, Pikussa RF, Oliveira T, Santos TM. As praças que a gente viu! As praças que a gente quer! In: XV Congresso Brasileiro de Ciências do Esporte. II Congresso Internacional de Ciências do Esporte - Política Científica e Produção do Conhecimento. Recife Anais: CBCE, 2007.

21. Marcellino NC. Lazer, Espaço Urbano e Transversalidade. In: Carvalho JE, Org. Lazer no espaço urbano: transversalidade e novas tecnologias. Curitiba: Champagnat, 2006: 71-82.

22. Florindo AA, Hallal PC, de Moura EC,Malta DC. Practice of physical activities and associated factors in adults, Brazil, 2006. Rev Saude Publica 2009; 43 Suppl 2:65-73.

23. Salvador EP, Florindo AA, Reis RS, Costa EF. Perception of the environment and leisure-time physical activity in the elderly. Rev Saude Publica 2009; 43:972-80.

24. Knuth AG, Bacchieri G, Victora CG, Hallal PC. Changes in physical activity among Brazilian adults over a 5-year period. J Epidemiol Community Health. 2010; 64(7):591-5. 